\title{
Preparation of opianic acid
}

\section{Wöhler}

To cite this article: M. Wöhler (1844) Preparation of opianic acid, Philosophical Magazine Series 3, 25:167, 396-397, DOI: 10.1080/14786444408645025

To link to this article: http://dx.doi.org/10.1080/14786444408645025

曲 Published online: 30 Apr 2009.

Submit your article to this journal $2 \pi$

Џ Article views: 2

Q View related articles $₫$ 
flocculi, which appear to be amorphous, but when examined by a strong magnifier they are seen to be composed of small four-sided and long fibrous crystals. Opianic acid acts in the same way with alcohol; and in this state it is insoluble in hot ammonia, and also in a solution of potash, unless long boiled in it.

It was found by analysis that the fused insoluble acid had the same composition as the soluble crystallized acid. The composition is stated by the author to be

$$
\begin{array}{lr}
\text { Carbon } \ldots . . & 57 \cdot 84 \text { or } \mathrm{C}^{20} \\
\text { Hydrogen } \ldots & 4 \cdot 29 \ldots \frac{\mathrm{H}^{8}}{} \\
\text { Oxygen } \ldots . & \frac{37 \cdot 87}{100^{\circ}} \ldots \overline{\mathrm{O}}^{9}
\end{array}
$$

combined with one equivalent of basic water.-Ann. de Ch. et de Phys., Octobre 1844.

\section{NATURE AND COMPOSITION OF SOME OPIANATES.}

M. Wöhler states that a boiling saturated solution of opianic acid dissolves the carbonate of barytes, Jime, lead and silver, with the disengagement of carbonic acid, and it forms soluble salts with these bases.

Opianate of barytes is very soluble and crystallizes in radiating prisms; it effloresces when heated, and loses six per cent., or two equivalents of water. Opianate of lead forms transparent, brilliant, mammillated crystals, which are but slightly soluble. It contains 5.45 per cent. of water or 2 equivalents; when heated, it first loses this water, then fuses and is eventually decomposed. At a certain temperature the salt crystallizes free'from water in small fasciculated silky crystals. It is soluble in alcohol.

Opianate of silver crystallizes in short transparent crystals, which when seen in mass have always a yellowish tint, which appears to be produced by the action of light, but it does not subsequently increase; it contains water, which it loses when heated and becomes opake; it fuses when more strongly heated, and when decomposed it yields a liquid of a fine green colour and metallic lustre; it afterwards assumes a deep red colour, and eventually leaves metallic silver; these colours appear to depend on the formation of a salt of the suboxide.-Ann. de Ch. et de Phys., Octobre 1844.

PREPaRATION OF OPIANIC ACID. BY M. WÖHLER.

To prepare this acid dissolve narcotina in an excess of dilute sulphuric acid, and add to the solution pure and very finely powdered binoxide of manganese, and boil the mixture. The reaction, which takes place immediately, is shown by the liquor becoming of a yellow colour, and the evolution of a small quantity of carbonic acid gas; the ebullition is to be continued as long as carbonic acid is evolved, adding cccasionally binoxide of manganese, so that there shall be excess of it at the end of the operation; and care must especially be taken that there is always an excess of acid. The liquor is to be filtered while hot, and it is of a reddish-yellow colour; on cooling it deposits a mass of opianic acid in small yellow crystals, 
which are to be separated by filtering paper, washed with cold water, and then strongly pressed between folds of filtering paper. They are then to be dissolved and boiled in a solution of hypochlorite of soda to decolorize them, and the solution is to be decomposed by gradually adding hydrochloric acid. The opianic acid usually crystallizes in a colourless state on the cooling of the liquid; after washing it with cold water, the acid is to le again pressed and purified by repeated crystallizations.

The liquor from which the crystals are originally obtained is to be treated afresh with sulphuric acid and manganese to obtain more of the acid.-Ann. de Ch. et de Phys., Octobre 1844.

\section{ON SIIICIC ETHERS. BY M. EBELMEN.}

The author has procured two definite combinations of æther with silica, by means of the action of absolute alcohol on chloride of silicium; the circumstances under which they are produced are the following :-

Cautiously pour absolute alcohol into chloride of silicium, and a vivid reaction takes place with a very abundant disengagement of hydrochloric acid gas, and a considerable reduction of temperature; when the weight of the alcohol added rather exceeds that of the chloride of silicium, no further disengagement of gas is perceived, and the liquor becomes very sensibly warm. If it be submitted to distillation, there first passes over a certain quantity of hydrochloric æther, and then the greater part of the liquid contained in the retort distils between $320^{\circ}$ and $340^{\circ} \mathrm{F}$; the latter product is to be set aside and the distillation is to be continued until it terminates at above $570^{\circ}$ F. ; there remains a mere trace of silica in the retort.

The product distilled between $320^{\circ}$ and $338^{\circ}$ was rectified until its boiling point became fixed between $323^{\circ}$ and $325^{\circ}$; by this there was obtained a colourless liquid, possessing a penetrating and æthereal odour, a strong hot taste, and its density was 0.932 . Water does not dissolve it, and decomposes it very slowly with a deposit of silica; it is perfectly neutral to test papers ; alcohol and ather dissolve it in all proportions; the alcoholic solutions of the alkalies decompose it rapidly, and by means of acids, silica is separated in the gelatinous state. When a few drops are thrown upon red.hot platina, they burn with a white flame, depositing silica in the state of an impalpable powder.

The analyses of this compound show that it contains carbon and hydrogen in the same proportions as in æether, and that the silica contains the same quantity of oxygen as the base.

If then 277.32 be admitted as the equivalent of silicium, as allowed by most chemists, and $\mathrm{SiO}^{5}$ for the formula of silica, that of the ather will be $\mathrm{SiO}^{3} 3 \mathrm{C}^{4} \mathrm{H}^{1} \mathrm{O}$. If, on the other hand, we take the third of the preceding number, or 9244 , as the equivalent of silicium, and $\mathrm{SiO}$ as the formula for silica, as proposed by M. Dumas, according to the density of the vapour of chloride of silicium, the formula for silicic æther will be similar to that of other compound athers, and represented by $\mathrm{SiOC}^{4} \mathrm{H}^{5} \mathrm{O}$. 